\title{
BASIC PROPERTIES OF POTASSIUM OXIDE SUPPORTED ON ZEOLITE Y STUDIED BY PYRROLE-TPD AND CATALYTIC CONVERSION OF METHYLBUTYNOL
}

\author{
Nuttinee Supamathanon, Jatuporn Wittayakun and Sanchai Prayoonpokarach* \\ School of Chemistry, Institute of Science, Suranaree University of Technology, Nakhon Ratchasima, 30000, Thailand \\ Wojciech Supronowicz and Frank Roessner \\ Industrial Chemistry 2, Institute of Pure and Applied Chemistry, Carl von Ossietzky University of Oldenburg, D-26111 Oldenburg, \\ Germany
}

Recebido em 14/10/11; aceito em 16/5/12; publicado na web em 24/8/12

\begin{abstract}
We report on the basic properties of zeolite $\mathrm{NaY}$ and potassium supported on $\mathrm{NaY}(\mathrm{K} / \mathrm{NaY})$ assessed by pyrrole-TPD and MBOH transformation. Pyrrole-TPD revealed that impregnation of zeolite NaY with potassium promoted additional adsorption sites for pyrrole compared to parent zeolite. For zeolite with various potassium loadings, pyrrole adsorbed on K/NaY decreased with increased potassium loading. Reduction in pyrrole adsorption could be due to potassium hindering intrinsic basic sites (lattice oxygen), to oxide of potassium occluding in zeolite cavities restricting access for pyrrole, or to $\mathrm{K}_{2} \mathrm{O}$ reacting with pyrrole to form nondesorbed pyrrolate anions. On $\mathrm{MBOH}$ transformation, potassium almost completely suppressed $\mathrm{NaY}$ acid sites while $\mathrm{K} / \mathrm{NaY}$ basicity increased with potassium loading.
\end{abstract}

Keywords: potassium on zeolite Y; pyrrole adsorption; $\mathrm{MBOH}$.

\section{INTRODUCTION}

We recently reported a preparation of base heterogeneous catalysts containing potassium supported on zeolite $\mathrm{NaY}(\mathrm{xK} / \mathrm{NaY}$ where $\mathrm{x}=4,8$ and $12 \% \mathrm{wt}$ loading of $\mathrm{K}$ ) by impregnation of a solution of potassium on the zeolite. ${ }^{1}$ This method prevented collapse of the zeolite structure and the catalysts obtained were effective for transesterification of Jatropha seed oil to produce biodiesel. Catalytic performance increased with potassium loading and complete conversion was observed on $12 \mathrm{~K} / \mathrm{NaY}$. The addition of potassium proved able to change the basic properties of the zeolite. Thus, we further investigated the basicity of the $\mathrm{NaY}$ and $\mathrm{xK} / \mathrm{NaY}$ catalysts.

Typically, oxygen atoms in the framework of zeolites are intrinsic Lewis basic sites which form acid-base pairs with the charge compensating cations. ${ }^{2}$ The basicity of zeolite can be further increased by impregnating it with a solution of alkali metal salt which can be decomposed to form oxides. The occlusion of alkali metal oxide clusters in the zeolite cages results in a further increase in basicity. ${ }^{3}$

A technique widely used to study the basic properties of solids is temperature programmed desorption of carbon dioxide $\left(\mathrm{CO}_{2}\right.$-TPD) in which the desorption temperatures reflect the strength of $\mathrm{CO}_{2}$ adsorption whereas the amount of desorbed $\mathrm{CO}_{2}$ correlates with the quantity of basic sites. Noiroj et al. ${ }^{4}$ used $\mathrm{CO}_{2}$-TPD to study the basic properties of $\mathrm{NaY}$ and $\mathrm{NaY}$ loaded with $10 \mathrm{wt} \% \mathrm{KOH}$. $\mathrm{CO}_{2}$ desorption on $\mathrm{NaY}$ occurred in the $100-300{ }^{\circ} \mathrm{C}$ range reaching a maximum at around $200{ }^{\circ} \mathrm{C}$ corresponding to adsorption on weak basic sites. Desorption on $\mathrm{KOH} / \mathrm{NaY}$ was observed in the $230-370{ }^{\circ} \mathrm{C}$ temperature range corresponding to adsorption on medium strength basic sites which were responsible for the catalytic activity for transesterification. Ramos et al. ${ }^{5}$ also used $\mathrm{CO}_{2}$-TPD to study basicity of catalysts prepared by loading sodium acetate solution on three different zeolites (mordenite, beta and X) to determine the influence of the zeolite type on biodiesel production. The modified zeolite $\mathrm{X}$ provided greater activity than the others because it contained a higher concentration

*e-mail: sanchaip@sut.ac.th of occluded sodium oxide species which acted as super basic sites.

However, the main drawback of $\mathrm{CO}_{2}$-TPD is the strong interaction of $\mathrm{CO}_{2}$ with basic sites, data for which may not reflect the correct number of basic sites. ${ }^{2}$ Consequently, pyrrole $\left(\mathrm{C}_{4} \mathrm{H}_{4} \mathrm{NH}\right)$, a five-membered ring heterocyclic aromatic compound may be used as an alternative probe molecule to characterize zeolite basicity. ${ }^{2,6,7}$ Pyrrole is an amphoteric molecule which can either interact with the Lewis basic oxygen of zeolite via the $\mathrm{NH}$ group by hydrogen bonding or with the Lewis acidic cation via the aromatic $\pi$-electrons interaction. ${ }^{7}$ Pyrrole can be used as a probe molecule in TPD for the characterization of basic sites because it can be adsorbed reversibly due to its weak acidity. ${ }^{3,7}$ In the present work, we applied pyrrole-TPD to study the basicity of $\mathrm{NaY}$ and $\mathrm{K} / \mathrm{NaY}$.

Furthermore, the basic properties of the $\mathrm{K} / \mathrm{NaY}$ catalysts were correlated with the catalytic activity on transformation of 2-methyl3-butyn-2-ol (MBOH). Products from different reaction pathways can be used to distinguish acidic and basic sites of a catalyst. ${ }^{8-10}$ The overall reaction pathways of $\mathrm{MBOH}$ are shown in Scheme 1 . In the presence of weak acidic sites, 3-methyl-3-buten-1-yne (MBYNE) is produced via dehydration of $\mathrm{MBOH}$. In the presence of strong acidic sites, 3-methyl-2-buten-1-al (prenal) is formed via isomerization of $\mathrm{MBOH}$. On the other hand, the coordinatively unsaturated (defect) sites lead to the formation of 3-hydroxy-3-methyl-2-butanone (HMB) and 3-methyl-3-buten-2-one (MIPK). Over the basic sites, acetone and acetylene are produced from the decomposition of $\mathrm{MBOH}$. The $\mathrm{MBOH}$ reaction has been used to test for the basic zeolite catalyst. For instance, Meyer and Hoelderich ${ }^{11}$ investigated the basic properties of various basic $\mathrm{NaX}$ zeolite catalysts prepared by ion exchange or impregnation with aqueous solution of cesium acetate and methanolic solution of sodium azide. The basic sites were generated in the zeolite after loading alkali metal cations and alkaline metal oxides by ion exchange and the impregnation method, respectively. The authors observed that both conversion of $\mathrm{MBOH}$ and selectivity for basic products correlated with the amount of cesium acetate decomposed on zeolite $\mathrm{NaX}$.

The aim of the present work was to investigate the basic properties of $\mathrm{NaY}$ and $\mathrm{K} / \mathrm{NaY}$ by pyrrole-TPD and transformation of $\mathrm{MBOH}$. 


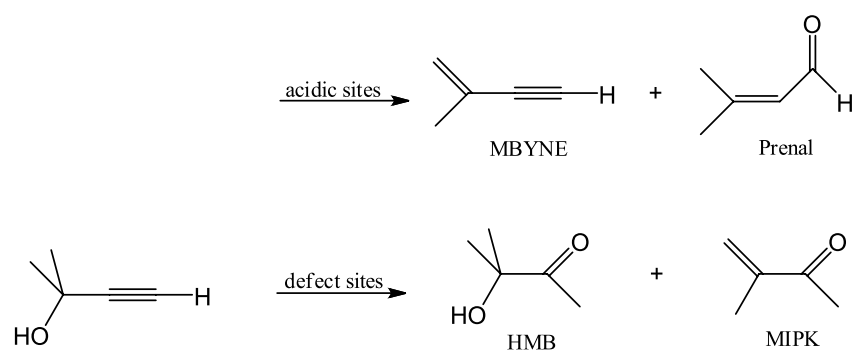

$\mathrm{MBOH}$

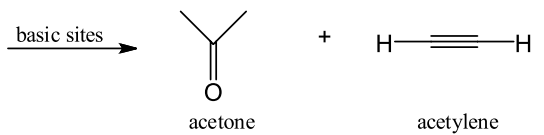

Scheme 1. Reaction pathways of $\mathrm{MBOH}$

\section{EXPERIMENTAL}

\section{Catalyst preparation}

The catalysts studied in this work were prepared by impregnating $\mathrm{NaY}$ with a solution containing a mixture of $\mathrm{CH}_{3} \mathrm{COOK} / \mathrm{CH}_{3} \mathrm{COOH}$ to give potassium loadings of 4,8 and $12 \mathrm{wt} \%$. The samples were dried in an oven at $30{ }^{\circ} \mathrm{C}$ for $4 \mathrm{~h}$ and at $80{ }^{\circ} \mathrm{C}$ overnight before calcination at $400{ }^{\circ} \mathrm{C}$ for $3 \mathrm{~h}$. The resultant samples were $4 \mathrm{~K} / \mathrm{NaY}, 8 \mathrm{~K} /$ $\mathrm{NaY}$ and $12 \mathrm{~K} / \mathrm{NaY}$.

\section{Pyrrole-TPD}

Pyrrole-TPD analysis was performed on an apparatus manufactured by Raczek Analysen Technik GmbH, Hannover (Germany). ${ }^{12}$ A $0.1 \mathrm{~g}$ sample with a particle size of 200-315 $\mu \mathrm{m}$ was placed into a plug flow quartz reactor which was coupled to a thermal conductivity detector (TCD). The prepared catalysts was then conditioned under a helium flow $(45 \mathrm{~mL} / \mathrm{min})$ to $350{ }^{\circ} \mathrm{C}$ at a heating rate of $10{ }^{\circ} \mathrm{C} / \mathrm{min}$ with the final temperature held for $1 \mathrm{~h}$. Subsequently, a helium flow saturated with pyrrole at $20{ }^{\circ} \mathrm{C}$ was fed at a flow rate of $59.3 \mathrm{~mL} /$ min over the conditioned catalyst at $55{ }^{\circ} \mathrm{C}$ for $45 \mathrm{~min}$. The physically adsorbed pyrrole was removed by flushing with helium at a flow rate of $45 \mathrm{~mL} / \mathrm{min}$ at $100{ }^{\circ} \mathrm{C}$ for $2 \mathrm{~h}$. Temperature programmed desorption (TPD) of the chemically adsorbed pyrrole was studied in the temperature range to $600{ }^{\circ} \mathrm{C}$ with a heating rate of $10^{\circ} \mathrm{C} / \mathrm{min}$ using helium as a carrier gas. Gaussian deconvolution of the TPD curve was performed using the Origin 6.0 program to identify peak positions and to integrate the peak area. To determine the amount of pyrrole, a calibration curve was constructed based on peak area versus number of moles of pyrrole corresponding to $0.5,0.8$ and $1.0 \mu \mathrm{L}$ of pyrrole directly injected into the quartz reactor. The TCD signals were recorded isothermally at $110{ }^{\circ} \mathrm{C}$. The amount of injected pyrrole in mol was calculated using Equation 1.

$$
\mathrm{n}_{\mathrm{Pyr}}=\frac{\rho_{\mathrm{Pyr}} \mathrm{V}_{\mathrm{Pyr}}}{\mathrm{M}_{\mathrm{Pyr}}}
$$

where $\rho_{\text {Pyr }}, V_{\text {Pyr }}$ and $\mathrm{M}_{\text {Pyr }}$ represent the density $\left(0.966 \mathrm{~g} \mathrm{~cm}^{-3}\right)$, volume $(\mu \mathrm{L})$ and molecular weight $\left(67.09 \mathrm{~g} \mathrm{~mol}^{-1}\right)$ of pyrrole, respectively.

\section{Transformation of $\mathrm{MBOH}$}

The transformation of $\mathrm{MBOH}$ was conducted in a fixed bed reactor controlled by an automated bench unit. ${ }^{12} \mathrm{MBOH}$ and toluene with a purity of $99 \%$ were obtained from Fluka and used without further purification. A catalyst weight of $20 \mathrm{mg}$ with a particle size of 200$315 \mu \mathrm{m}$ placed in the central section of a quartz tubular reactor was heated to $350{ }^{\circ} \mathrm{C}$ at a rate of $8{ }^{\circ} \mathrm{C} / \mathrm{min}$ and kept at this temperature for $4 \mathrm{~h}$ under nitrogen flow $(13.7 \mathrm{~mL} / \mathrm{min})$ to remove any adsorbed compounds from the surface. After catalyst activation, the reactor temperature was lowered to $120{ }^{\circ} \mathrm{C}$. A solution mixture of $\mathrm{MBOH}$ (95 vol\%) and toluene (5 vol\%, as an internal standard) placed and cooled in a storage vessel at $13{ }^{\circ} \mathrm{C}$ was fed into an evaporator. The vapor produced was passed through a capillary in which a static nitrogen pressure of 2 bars was applied to obtain a gas flow rate of 0.02 $\mathrm{mL} / \mathrm{min}$. The gas stream was flowed over the catalyst in the reactor where the temperature was maintained at $120^{\circ} \mathrm{C}$. The outlet gas was analyzed on-line using a HP 8090 Series II gas chromatograph with a $60 \mathrm{~m}$ Optima Wax capillary column. The $\mathrm{MBOH}$ conversion $\left(\mathrm{X}_{\mathrm{MBOH}}\right)$, yield $(\mathrm{Y})$ and selectivity $(\mathrm{S})$ of each product from the transformation of $\mathrm{MBOH}$ were calculated by Equation 2-4, respectively.

$$
\begin{gathered}
X_{\mathrm{MBOH}}(\%)=\frac{n_{\mathrm{MBOH}, \text { in }}-n_{\mathrm{MBOH}, \text { out }}}{n_{\mathrm{MBOH}, \text { in }}} \times 100 \\
Y_{\mathrm{P}}(\%)=\frac{A_{P} R_{P} / M_{P}}{\sum_{K} A_{K} R_{K} / M_{K}} \times 100 \\
\mathrm{~S}_{\mathrm{p}}(\%)=\frac{\mathrm{Y}_{\mathrm{p}}}{\mathrm{X}_{\mathrm{MBOH}}} \times 100
\end{gathered}
$$

where $A_{p}, R_{P}, M_{p}, S_{p}$ and $Y_{P}$ represent the area, response factor, mass, selectivity and yield of product $P$, respectively. $A_{K}, R_{K}$ and $M_{K}$ represent the area, response factor and mass of all components.

\section{RESULTS AND DISCUSSION}

\section{Pyrrole-TPD}

The pyrrole-TPD profiles of $\mathrm{NaY}$ and $\mathrm{xK} / \mathrm{NaY}$ are shown in Figure 1. Using a similar procedure for each sample, NaY yielded the most intense TCD signal. For the K/NaY samples, curve intensity decreased as the potassium loading was increased. The total peak area of each curve and the corresponding amount of pyrrole per gram of the catalyst, calculated from the calibration curve, are listed in Table 1. It was reported that the surface area of $\mathrm{K} / \mathrm{NaY}$ decreases linearly as the potassium loading is increased. ${ }^{1}$ In the present case, the adsorbed amount of pyrrole also decreased linearly with increased potassium loading $\left(\mathrm{R}^{2}=0.9898\right)$. Thus, the amount of adsorbed pyrrole was related directly to the surface area. The specific amount of pyrrole ( $\mathrm{mmol}$ per surface area) on all catalysts was similar, at approximately $0.02 \mathrm{mmol} / \mathrm{m}^{2}$. It was likely that the oxide of potassium occluded in the zeolite cavities, rendering them smaller and less accessible for pyrrole molecules. ${ }^{13,14}$ By comparing the TPD profiles of the $\mathrm{K} / \mathrm{NaY}$ samples with that of $\mathrm{NaY}$, an additional shoulder was observed at around $150{ }^{\circ} \mathrm{C}$ suggesting that loading the zeolite with potassium generated additional adsorption sites. According to Doskocil et al. and Lavalley, potassium can generate species such as $\mathrm{K}_{2} \mathrm{O}$ which act as the strong base and can generate pyrrolate anion $\left(\mathrm{C}_{4} \mathrm{H}_{4} \mathrm{~N}^{-}\right)$.,15 The pyrrolate anion interacted with surface hydroxyl groups which are less basic and thus, the pyrrole desorption occurred at a lower temperature. ${ }^{3,15}$ Furthermore, this model could explain the decrease in the desorbed amount of pyrrole with increasing potassium content, since the formed pyrrolate cannot desorb under the given conditions.

The pyrrole molecule interacts with zeolite via a hydrogen bond between the $\mathrm{NH}$ group and lattice oxygen which acts as the Lewis basic sites and interaction of pyrrole aromatic electrons with the 
Table 1. Results from pyrrole-TPD

\begin{tabular}{|c|c|c|c|c|c|c|c|}
\hline \multirow{2}{*}{$\begin{array}{c}\text { Sample } \\
\mathrm{NaY}\end{array}$} & \multirow{2}{*}{$\begin{array}{c}\text { Total peak area } \\
\text { (area/g) }\end{array}$} & \multirow{2}{*}{$\begin{array}{c}\begin{array}{c}\text { Amount of pyr- } \\
\text { role }(\mathrm{mmol} / \mathrm{g})\end{array} \\
19.9\end{array}$} & \multirow{2}{*}{$\begin{array}{l}\begin{array}{l}\text { Amount of pyr- } \\
\text { role per surface } \\
\text { area }\left(\mathrm{mmol} / \mathrm{m}^{2}\right)\end{array} \\
0.0213\end{array}$} & \multicolumn{4}{|c|}{$\begin{array}{l}\text { Peak of desorption temperature }\left({ }^{\circ} \mathrm{C}\right) \text { from deconvolution and } \\
\text { corresponding peak area }(\%)\end{array}$} \\
\hline & & & & & $207(22.6 \%)$ & $259(17.4 \%)$ & $288(59.9 \%)$ \\
\hline $4 \mathrm{~K} / \mathrm{NaY}$ & 64,498 & 14.4 & 0.0198 & $160(7.8 \%)$ & $210(19.7 \%)$ & $266(61.7 \%)$ & $299(10.6 \%)$ \\
\hline $8 \mathrm{~K} / \mathrm{NaY}$ & 47,108 & 10.5 & 0.0208 & $161(9.5 \%)$ & $210(30.8 \%)$ & $257(11.7 \%)$ & $303(47.8 \%)$ \\
\hline $12 \mathrm{~K} / \mathrm{NaY}$ & 30,750 & 6.8 & 0.0192 & $155(6.0 \%)$ & $195(20.6 \%)$ & $260(52.0 \%)$ & $312(21.2 \%)$ \\
\hline
\end{tabular}
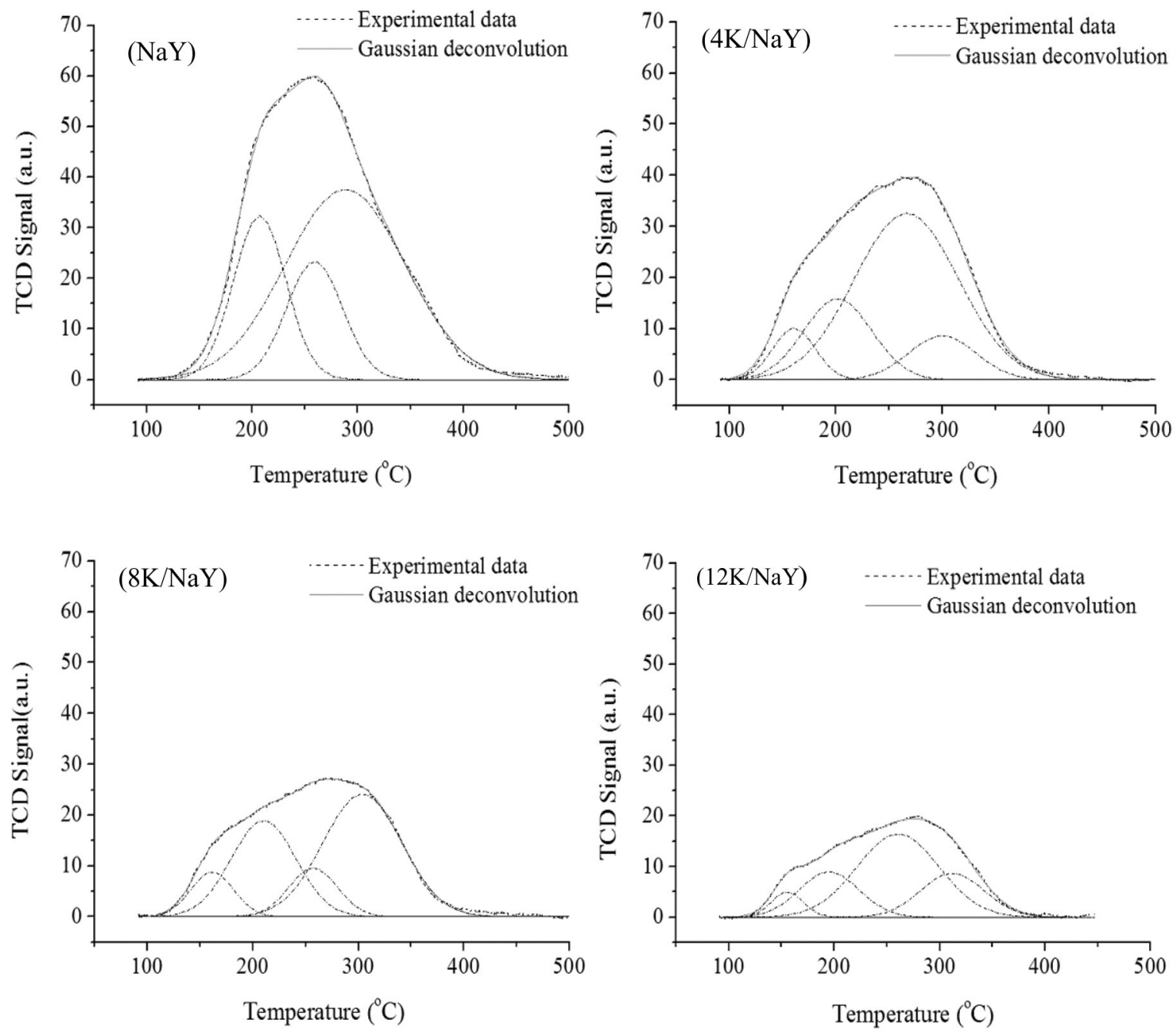

Figure 1. Experimental and deconvolution of TPD peaks of pyrrole on $\mathrm{NaY}, 4 \mathrm{~K} / \mathrm{NaY}, 8 \mathrm{~K} / \mathrm{NaY}$ and $12 \mathrm{~K} / \mathrm{NaY}$

cations (Na ions) which are Lewis acidic sites. With potassium loading by impregnation, the cations were able to interact with the Lewis basic sites, hinder adsorption of pyrrole and result in less hydrogen bonding. The potassium ions also interacted with the aromatic electrons. Moreover, in the event that some potassium cations exchanged with the $\mathrm{Na}$ cations, the basicity can be enhanced according to the difference in cationic size..$^{7,13,14}$

Because the peak positions in all samples were not clearly resolved, deconvolutions of the TPD profiles were generated (Figure 1). There were three peaks for $\mathrm{NaY}$ and four peaks for the $\mathrm{K} / \mathrm{NaY}$ samples. The additional peak in the profiles of the $\mathrm{K} / \mathrm{NaY}$ samples can be assigned to the additional adsorption sites, potassium ions, which interacted with pyrrole. The difference in the cationic size of potassium and sodium resulted in different adsorption strength.

\section{Transformation of $\mathrm{MBOH}$}

Because the test reaction of $\mathrm{MBOH}$ transformation was able to distinguish between acidic, basic and coordinatively unsaturated active sites, the change in basicity can be compared directly from the product selectivity. Selectivity over the $\mathrm{NaY}$ and $\mathrm{K} / \mathrm{NaY}$ samples are shown in Figure 2. The reaction over the NaY zeolite catalyst generated main products from basic pathway (acetone and acetylene) with a significant amount of MBYNE which is a product from the acidic pathway (Figure 2a). Thus, the surface of the NaY zeolite contained predominantly basic sites and a moderate number of acidic sites. This observation was in strong agreement with reports in the literature. ${ }^{16}$ The products from the amphoteric pathway (HMB and MIPK) were not significant in all catalysts. In contrast, all the $\mathrm{K} / \mathrm{NaY}$ samples 

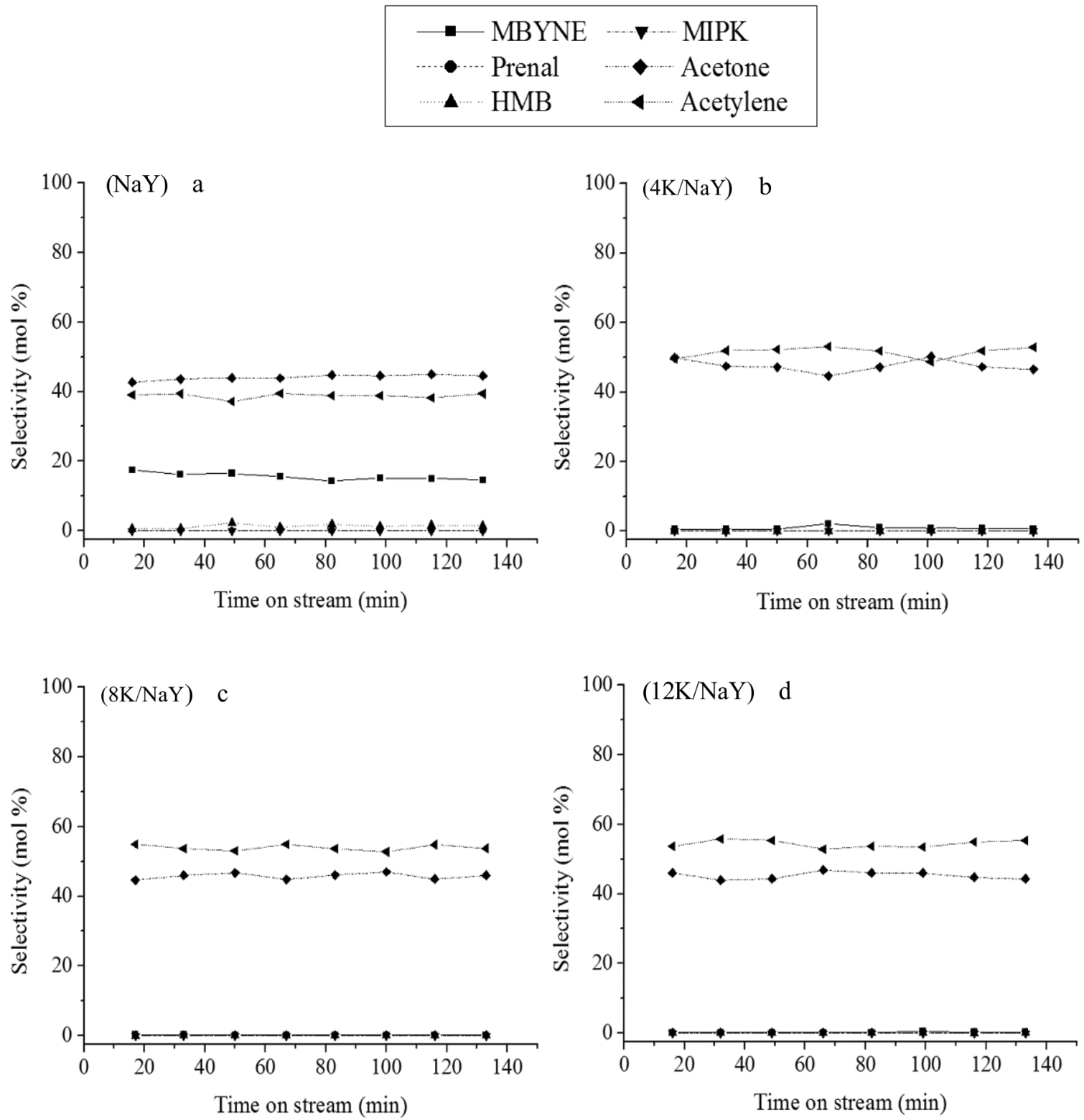

Figure 2. Selectivity of the product of $\mathrm{MBOH}$ test reaction over $\mathrm{NaY}, 4 \mathrm{~K} / \mathrm{NaY}, 8 \mathrm{~K} / \mathrm{NaY}$, and $12 \mathrm{~K} / \mathrm{NaY}$ catalyst, reaction temperature, $120{ }^{\circ} \mathrm{C}$; amount of catalyst, $0.020 \mathrm{~g}$

generated acetone and acetylene as the major products (Figure $2 b-$ d) confirming their basicity. The amount of MBYNE was less than $0.9 \%$ for $4 \mathrm{~K} / \mathrm{NaY}$ and less than $0.3 \%$ for $8 \mathrm{~K} / \mathrm{NaY}$ and $12 \mathrm{~K} / \mathrm{NaY}$. These results indicated that impregnation with potassium suppressed the acidic sites of $\mathrm{NaY}$ zeolite by solid state ion exchange and that all the prepared catalysts were basic in nature. The molar ratio between acetone and acetylene $(0.93,0.90$ and 0.85 of $4 \mathrm{KNaY}, 8 \mathrm{~K} /$ $\mathrm{NaY}$ and $12 \mathrm{~K} / \mathrm{NaY}$, respectively) was less than the theoretical value, 1.00 , probably because of aldol condensation of acetone producing condensation products which adsorbed strongly on the surface..$^{17,18}$

The conversions of $\mathrm{MBOH}$ over the $\mathrm{NaY}$ and $\mathrm{K} / \mathrm{NaY}$ samples are shown in Figure 3. The conversion on $\mathrm{NaY}$ was significantly lower than those of the $\mathrm{K} / \mathrm{NaY}$ samples indicating that impregnation with potassium increased the active sites. In the first $80 \mathrm{~min}$, conversion on $\mathrm{K} / \mathrm{NaY}$ increased with potassium loading but after that the conversion on $12 \mathrm{~K} / \mathrm{NaY}$ was similar to that on $8 \mathrm{~K} / \mathrm{NaY}$. The absence of any difference was probably caused by the high degree of conversion which does not allow differentiation between the two samples. To confirm this hypothesis, the amount of the two catalysts $(8 \mathrm{~K} / \mathrm{NaY}$ and

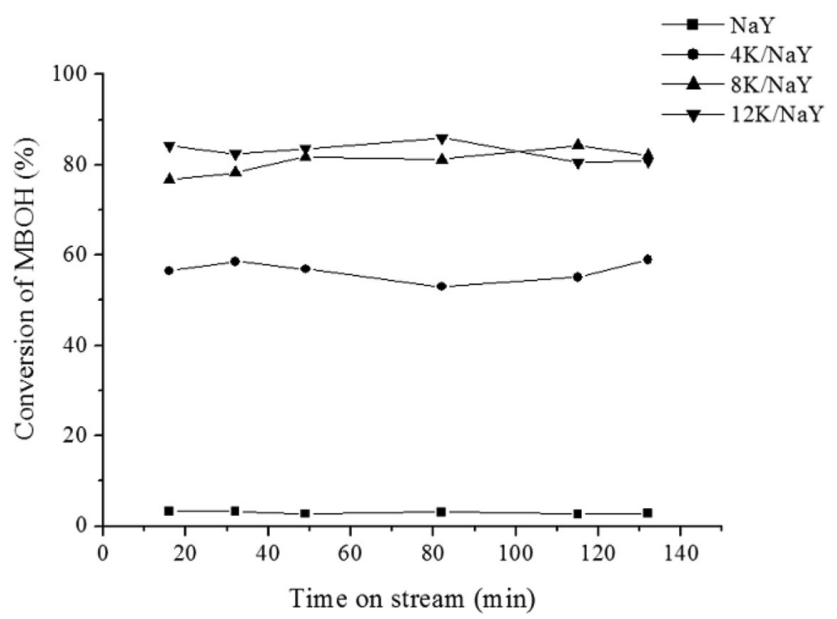

Figure 3. Conversion of $\mathrm{MBOH}$ test reaction over the parent $\mathrm{NaY}$ and $x \mathrm{~K} /$ $\mathrm{NaY}$ catalysts with 4,8 and $12 \mathrm{wt} \%$ loading, reaction temperature, $120{ }^{\circ} \mathrm{C}$; amount of catalyst, $0.020 \mathrm{~g}$ 
$12 \mathrm{~K} / \mathrm{NaY}$ ) for the $\mathrm{MBOH}$ test reaction was decreased from 0.02 to $0.01 \mathrm{~g}$ and the conversions compared again (Figure 4 ). The products from the basic pathway were still predominant in both catalysts (not shown). The conversion on $12 \mathrm{~K} / \mathrm{NaY}$ was higher than that on $8 \mathrm{~K} /$ $\mathrm{NaY}$ confirming the assumption that the strength of basic sites of $\mathrm{K} /$ $\mathrm{NaY}$ increased with potassium loading. The information on basicity of these catalysts were in good agreement with their catalytic performance on transesterification of Jatropha seed oil in which conversion and biodiesel yield increased with potassium loading. ${ }^{1}$

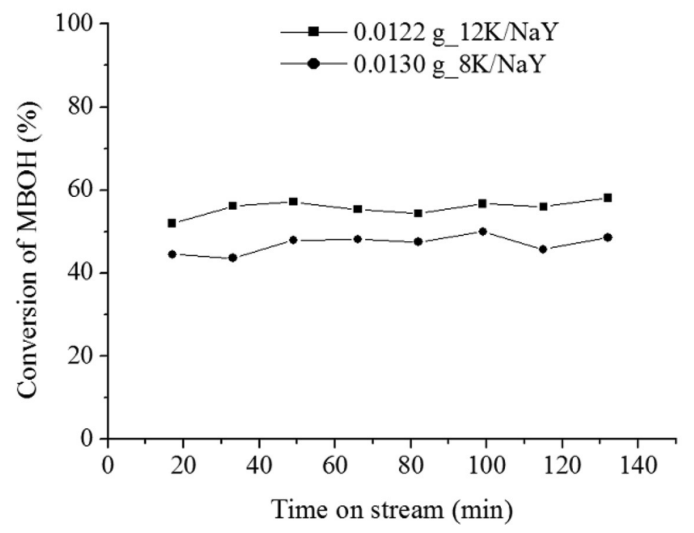

Figure 4. Conversion of $\mathrm{MBOH}$ test reaction over the $8 \mathrm{~K} / \mathrm{NaY}$ and $12 \mathrm{~K} / \mathrm{NaY}$ catalysts, reaction temperature, $120^{\circ} \mathrm{C}$; amount of catalyst, $0.01 \mathrm{~g}$

\section{CONCLUSION}

The basic properties of $\mathrm{K} / \mathrm{NaY}$ were studied by pyrrole-TPD and the $\mathrm{MBOH}$ test reaction. Pyrrole-TPD indicated at decrease in adsorption sites after impregnation of potassium on $\mathrm{NaY}$ in accordance with the decrease in surface area. The nature of pyrrole adsorption on the $\mathrm{K} / \mathrm{NaY}$ samples was different to that on $\mathrm{NaY}$ because potassium ions can hinder the intrinsic basic site (lattice oxygen) and possibly occluded in the zeolite cavities preventing the access of pyrrole. The potassium ions can also interact with the aromatic electrons of pyrrole. The difference in cation size between impregnated potassium and original sodium on the zeolite resulted in additional adsorption sites.
Further study by $\mathrm{MBOH}$ test reaction revealed that impregnation of potassium almost completely suppressed the acidic sites of $\mathrm{NaY}$ while the basicity of $\mathrm{K} / \mathrm{NaY}$ samples increased with potassium loading.

\section{ACKNOWLEDGEMENT}

This research was supported by Suranaree University of Technology, Thailand. The scholarship for N. Supamathanon was from Rajamangala University of Technology Isan, Thailand.

\section{REFERENCES}

1. Supamathanon, N.; Wittayakun, J.; Prayoonpokharach, S.; J. Ind. Eng. Chem. 2011, 17, 182.

2. Barthomeuf, D.; Catal. Rev.: Sci. Eng. 1996, 38, 512.

3. Doskocil, E. J.; Bordawekar, S.; Davis, R. J. In Catalysis; Spivey, J. J., ed.; Royal Society of Chemistry: Cambridge, 2000, vol. 15, chap. 2.

4. Noiroj, K.; Intarapong, P.; Luengnaruemitchai, A.; Jai-In, S.; Renew. Energ. 2009, 34, 1145.

5. Ramos, M. J.; Casas, A.; Rodríguez, L.; Romero, R.; Pérez, A.; Appl. Catal., A 2008, 346, 79.

6. Hattori, H.; Chem. Rev. 1995, 95, 537.

7. Förster, H.; Fuess, H.; Geidel, E.; Hunger, B.; Jobic, H.; Kirschhock, C.; Klepel, O.; Krause, K.; Phys. Chem. Chem. Phys. 1999, 1, 593.

8. Lauron-Pernot, H.; Luck, F.; Popa, J. M.; Appl. Catal. 1991, 78, 213.

9. Handa, H.; Fu, Y.; Baba, T.; Ono, Y.; Catal. Lett. 1999, 59, 195.

10. Brei, V. V.; Theor. Exp. Chem. 2008, 44, 320.

11. Meyer, U.; Hoelderich, W. F.; J. Mol. Catal. A: Chem. 1999, 142, 213.

12. Kuśtrowski, P.; Chmielarz, L.; Boźek, E.; Sawalha, M.; Roessner, F.; Mater. Res. Bull. 2004, 39, 263.

13. Sánchez, M. S.; Blasco, T.; J. Am. Chem. Soc. 2002, 124, 3443.

14. Heidler, R.; Janssens, G. O. A.; Mortier, W. J.; Schoonheydt, R. A.; Microporous Mater. 1997, 12, 1.

15. Lavalley, J. C.; Catal. Today 1996, 27, 377.

16. Huang, M.; Kaliaguine, S.; Catal. Lett. 1993, 18, 373.

17. Corma, A.; Iborra, S.; Adv. Catal. 2006, 49, 239.

18. Aramendía, M. A.; Boráu, V.; García, I. M.; Jiménez, C.; Marinas, A.; Marinas, J. M.; Porras, A.; Urbano, F. J.; Appl. Catal., A 1999, 184, 115. 